\title{
A qualitative study conducted in the USA exploring Latino fathers' beliefs, attitudes and practices related to their young children's eating, physical activity and sedentary behaviours
}

\author{
Ana Cristina Lindsay ${ }^{1,2, *}$, Sherrie F Wallington ${ }^{3}$, Mario A Muñoz ${ }^{1}$ and Mary L Greaney ${ }^{4}$ \\ 'Department of Exercise and Health Sciences, College of Nursing and Health Sciences, University of Massachusetts- \\ Boston, 100 Morrissey Boulevard, Boston, MA 02 125, USA: ${ }^{2}$ Department of Nutrition, Harvard T.H. Chan School of \\ Public Health, Boston, MA, USA: ${ }^{3}$ Lombardi Comprehensive Cancer Center, Georgetown University Medical Center, \\ Washington, DC, USA: ${ }^{4}$ Health Studies and Department of Kinesiology, University of Rhode Island, Kingston, RI, USA
}

Submitted 20 June 2017: Final revision received 9 August 2017: Accepted 11 August 2017: First published online 10 0ctober 2017

\begin{abstract}
Objective: Increasing evidence documents fathers' influential role in their children's eating, physical activity (PA) and sedentary behaviours (SB). We aimed to expand limited existing research examining fathers' influence in these areas by exploring Latino fathers' beliefs, attitudes and practices related to eating, PA and SB of their young children.

Design: Seven focus group discussions were conducted in Spanish with Latino fathers ( $n$ 28) of children aged 2-8 years. Audio recordings were transcribed and translated verbatim without identifiers. Data were analysed using thematic analysis to identify key concepts and themes using NVivo 11 software.

Results: Fathers expressed positive beliefs and attitudes about the importance of healthy eating for their young children, themselves and their families. Nevertheless, the majority reported familial practices including eating out, getting takeout, etc. that have been linked to increased obesity risk among Latino children. Fathers were more involved and engaged in children's PA than eating and feeding. However, several fathers reported engaging predominantly in sedentary activities with their children, appeared permissive of children's sedentary habits and struggled to set limits on children's screen-time.

Conclusions: We provide new information on Latino fathers' beliefs and child feeding and PA practices that may provide important targets for interventions aimed at promoting healthful eating and PA behaviours of Latino children. Future research should further quantify the influence of Latino fathers' parenting styles and practices on development of children's eating, PA and SB. This information is needed to identify risk factors amenable to interventions and to design culturally appropriate parenting and family-based interventions targeting Latino children's home environment and designed to meet this ethnic group's specific needs.
\end{abstract}

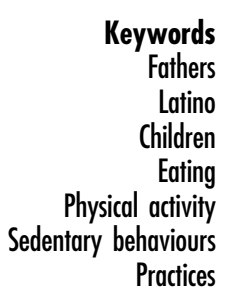

Latinos and Hispanics (hereafter referred to as 'Latinos') are the largest and most rapidly growing population group in the USA ${ }^{(1)}$. Children in low-income Latino families have an elevated risk of becoming overweight or obese ${ }^{(2)}$. Recent statistics show that almost $17 \%$ of Latino preschool children are classified as being obese compared with $11 \%$ of Black, $4 \%$ of White and $3 \%$ of Asian children $^{(2)}$. As a result, childhood obesity among Latinos is a pressing public health concern as childhood weight status tracks into adulthood and increases risk of other obesity-related chronic diseases ${ }^{(2,3)}$.

Establishing healthy eating and physical activity (PA) habits early in life is important for preventing obesity and related co-morbidities in childhood and beyond ${ }^{(4-6)}$. Multiple behavioural risk factors such as unhealthy eating habits (e.g. consumption of energy-dense, nutrient-poor foods), low PA levels and increased sedentary behaviours (SB) have been linked to disparities in childhood obesity among Latino children ${ }^{(2,3,6)}$. Parents are key players in determining their children's weight status through the home environment they create for eating, PA and $\mathrm{SB}^{(4,7-11)}$. Furthermore, parents shape their children's eating, PA and SB through their knowledge of nutrition; influence over food selection, meal structure and home eating patterns; and modelling of eating, PA and SB, including television (TV) viewing and screen time ${ }^{(4,8,10-12)}$. 
Due to parental influences on their children's eating and PA practices, and thus in preventing obesity, parents should be central to collective efforts to end the childhood obesity epidemic ${ }^{(4,5,12)}$.

To date, research examining parental influences on children's healthy eating, PA and SB has focused primarily on mother-child interactions ${ }^{(3,6-11,13-20)}$. This research documents the critical influence of mothers' beliefs, attitudes, parenting styles and practices on children's eating, PA, SB and weight status ${ }^{(10,11,13-20)}$. Although, in most cultures, mothers still spend more time caring for their children, fathers' involvement in childcare has increased over the past decades, especially in high-income countries $^{(21-25)}$. This increase may be due to changes in the labour market, increased participation of women in the labour force and changes in family roles and dynamics $^{(23,26)}$

Recent reviews point to the limited representation of fathers in parenting and childhood obesity research ${ }^{(27-30)}$. Despite the increasing number of studies examining fathers' food parenting practices ${ }^{(31-35)}$, available research assessing the influence of parenting styles and practices on children's eating among Latino fathers is limited ${ }^{(36-40)}$. None the less, these studies underscore father's influential role on children's eating ${ }^{(36-40)}$. This small body of research indicates the need for further research, but also suggests that Latino fathers be included in nutrition interventions designed to reduce and prevent child obesity ${ }^{(36-40)}$. Similarly, a growing research literature documents the influential role of fathers on children's PA and SB, but the majority of this research has focused on Caucasian, middle-income fathers ${ }^{(39,41)}$ with limited research examining Latino fathers' beliefs, attitudes and practices related to young children's PA and $\mathrm{SB}^{(39,41)}$. Results of a recent review that included thirteen studies examining home environmental influences on childhood obesity among Latino children (2-17 years) revealed that Latino children spend more time using media (e.g. watching TV, playing video games) and have fewer limitations placed on them by their parents regarding the use of media than White or Black children and that this lack of limits is associated with increased inactivity and child weight gain ${ }^{(7)}$. The majority of studies included in that review were composed primarily of Latina mothers, highlighting the need for additional studies to include Latino fathers ${ }^{(7)}$.

Identifying and understanding potentially modifiable factors associated with increased risk of child obesity among minority, low-income children, such as Latinos, is critical to collective efforts to prevent and control childhood obesity ${ }^{(3,6)}$. Given limited but increasing evidence of the influential role of fathers in their children's development of eating, $\mathrm{PA}$ and $\mathrm{SB}$, the purpose of the present study was to expand on the current existing research and examine Latino fathers' beliefs, attitudes and practices related to their young children's eating, PA and SB.

\section{Methods}

\section{Study design and sample}

The present study was part of a community-based, mixedmethods research study designed to assess parenting styles and practices related to eating, PA and SB associated with risk of childhood obesity that is being conducted with Latino families living in the state of Rhode Island, USA ${ }^{(42)}$. We used a purposive sampling method to recruit participants from Special Supplemental Nutrition Program for Women, Infants, and Children (WIC) clinics and community-based programmes and agencies serving predominantly Latino populations in Rhode Island. Clinics and community-based programmes and agencies were contacted by a research coordinator who explained the purpose of the research and asked the sites to participate in recruitment efforts. Sites agreeing to participate were mailed study flyers in Spanish and English that included a telephone number for interested participants to call. Flyers were posted at agencies between June and October 2016. Individuals who contacted the research coordinator were screened for study eligibility. Fathers were eligible to participate if they self-identified as being of Hispanic ethnicity; were 21 years of age or older; had lived in the USA for at least 12 months; had at least one child between 2 and 8 years of age who was enrolled in or eligible for WIC; and had shared parental responsibilities for or cohabitated with said child. Initial eligibility included being a parent of at least one child between 2 and 5 years of age, which is the age group eligible for the WIC programme. However, to recruit a sufficient number of fathers, we extended the age limit to 8 years, given that most eligible families had children of multiple ages.

We chose to conduct focus group discussions (FGD) because they are an important technique for conducting research in diverse cultural settings and provide valuable information ${ }^{(43,44)}$. Moreover, the synergistic effects of group settings elicit ideas and discussion that may not arise in individual interviews ${ }^{(43,44)}$. Ethics approval was obtained from the University of Massachusetts-Boston Ethics Board (IRB\# 2013060).

\section{Data collection}

We conducted seven FGD with Latino fathers at local public libraries and community agencies between August and October 2016. Each FGD had three to five participants. All FGD were conducted in Spanish and moderated by a bilingual native Spanish-speaker, trained in qualitative research methods, using a semi-structured discussion guide that explored fathers': (i) definitions of healthy eating and active living; (ii) beliefs and attitudes related to healthy eating, PA and SB of young children; (iii) practices related to eating, PA and SB; and (iv) perceptions of barriers to children's healthy eating and PA (Table 1). The FGD guide was piloted-tested in an FGD with Latino fathers not included in the present study and refined prior to use. 
Table 1 Questions from the focus group discussion guide on Latino fathers' beliefs, attitudes and practices related to their young children's eating, physical activity and sedentary behaviours

\begin{tabular}{ll}
\hline Topic & Discussion guide questions \\
\hline
\end{tabular}

Father's beliefs, attitudes and practices related to child eating and feeding

Beliefs and attitudes related to healthy eating

Perceptions of child's eating and feeding experiences

Practices related to child's eating and feeding at home

Fathers' personal healthy eating practices and desire for personal changes

Father's beliefs, perceptions and practices related to child physical activity

Beliefs and perceptions of children's physical activity at home

Practices related to screen time at home

Fathers' personal physical activity and sedentary behaviours and desire for personal changes
What does healthy eating mean to you?

Probes: How would you describe a 'healthy meal'? How do you decide if a food is good for health? What foods do you think are good for health?

In general, how satisfied are you with the types and amount of food your child eats?

Probes: Why? Is it the same as what the rest of family eats? Is it culturally appropriate? Is it healthy?

What are some foods that you wish your child would eat more of or more often?

Probes: Why?

What food do you wish your child would eat less often? Probes: Why?

What are your biggest concerns about how your child eats? Probes: Do you ever worry your child does not eat enough? Do you ever worry that your child eats too much? Do you ever worry about not having enough food to provide to your child?

Describe a typical mealtime routine at your home.

Probes: Who regularly prepares the meal? Who is present at the meal? Regularity of mealtime? Do you usually sit together as a family to eat? Does your child eat separately from the rest of the family? Does your child eat the same type of food as the rest of the family? Is the TV usually on during mealtimes?

How are decisions made about what foods to feed your child? Probes: healthy foods; cost/convenience; cultural values and traditions according to advice or direction from another person? If yes, probe further: What is that person's role or relationship to you/your child?

Describe any limits to eating that you set for your child during meals. Probes: How about snacks? Any particular types of foods and/or drinks not allowed?

In general, how satisfied are you with the types and amount of food you eat? Probes: Why? Is it the same as what the rest of family eats? Is it culturally appropriate? Is it healthy?

How important do you think it is for children to be physically active? Probes: Do you think it is a problem for kids to spend too much time being sedentary or not being physically active?

How much physical activity do you think children need? Probes: Why?

How physically active is your child at home? Probes: Plays actively outside? Plays actively inside? Does not play actively when at home?

In general, how satisfied are you with the amount of physical activity your child engages in?

Probes: Why? Do you wish he or she would be more active? Do you wish he or she had more outdoor playtime?

What are some types of physical activity or active play your child engages in while at home?

Probes: Riding his or her bike? Playing in nearby playground or park?

What are your biggest concerns about how physically active your child is? Probes: Do you ever worry your child does not engage in enough physical activity? Do you ever worry that your child is too sedentary?

What types of things would you like to change about how physically active your child is at home?

Probes: Amount? Types of activity?

Do you have any rule at home for your child regarding TV and/or video time or playtime with electronics?

Probes: Time limit on TV and electronics? Not allowing electronics in home?

What kinds of rules or practices do you have at home regarding your child watching TV and/or videos or playing with electronics?

Probes: Time limit on TV and electronics? Not allowing the TV on during meals? Not allowing TV during the week?

Does your child own his or her own TV, computer or portable video game equipment?

Probes: Do you let your child keep these electronics at all times?

In general, how satisfied are you with the amount of physical activity you engage in?

Probes: Why? Do you wish you would be more active? If desire changes, what would you change in your physical activity behaviours? 


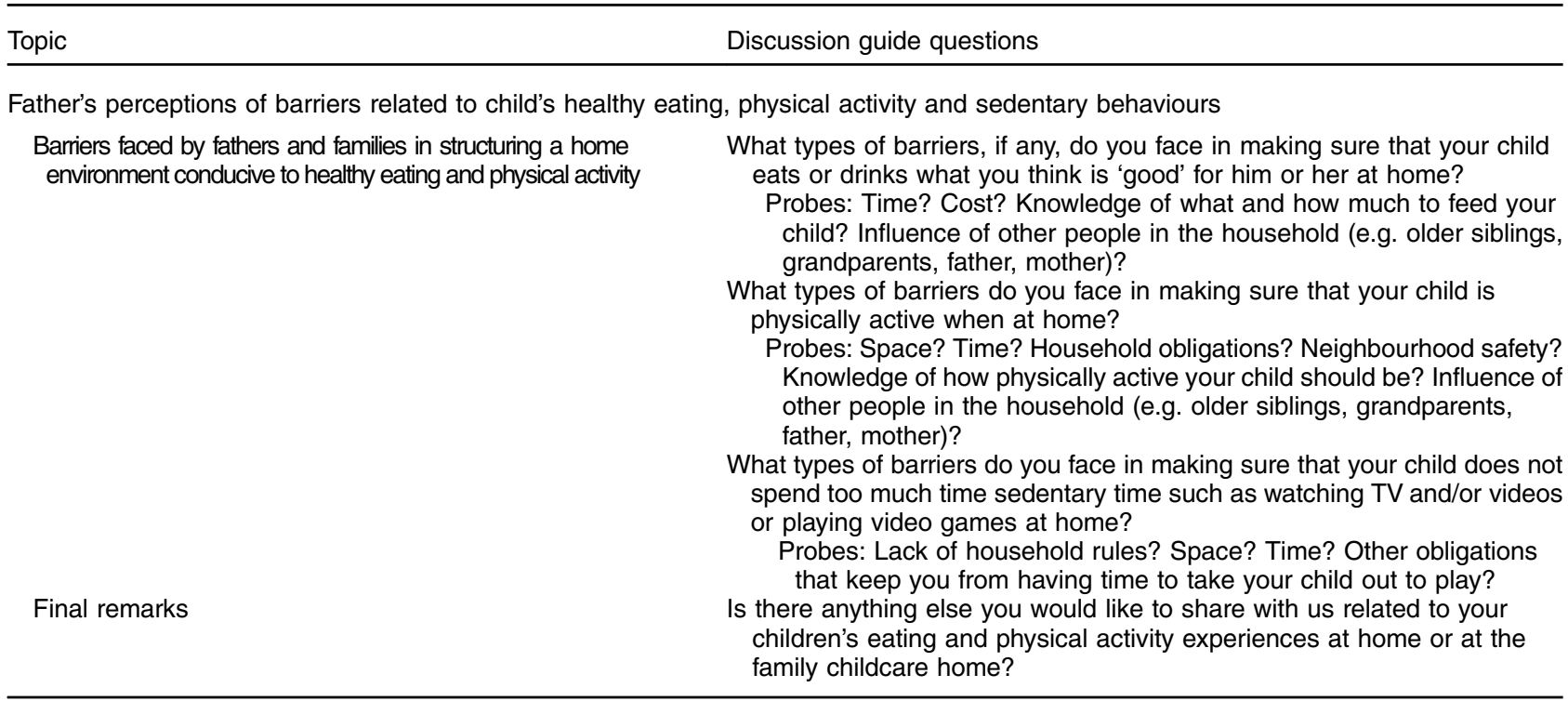

TV, television.

Before each FGD, the moderator explained the study's purpose and procedures, and participants provided written, informed consent. Before beginning each FGD, the moderator asked fathers to think about their youngest child (2-8 years of age) when participating in the discussion. Each audio-taped FGD lasted between 60 and $80 \mathrm{~min}$, and a trained, bilingual (Spanish and English) research assistant took notes during each session. The moderator and research assistant convened for approximately 15 min after the end of each FGD to discuss new and recurring themes heard during the session, which were then added as probes to the FGD guide.

At the completion of the FGD, participants received a \$US 25 gift card for participation and completed a brief, self-administered survey that assessed participants' sociodemographic characteristics (e.g. education, marital status, country of origin, length of time living in the USA, etc.) and level of acculturation via the Short Acculturation Scale for Hispanics $(\mathrm{SASH})^{(45)}$. The SASH is a twelve-item measuring scale validated for use in Latino groups, such as Mexican Americans, Cuban Americans, Puerto Ricans, Dominicans, and Central and South Americans ${ }^{(45)}$. The SASH assesses language use, media use and ethnic social relations. An acculturation score was computed by averaging across twelve items; measured on a scale of 1 (= least acculturated) to 5 (= fully acculturated) ${ }^{(45)}$.

\section{Analysis}

Audio tapes were transcribed verbatim in Spanish and translated into English without identifiers. To ensure that the integrity and equivalence of the data were not lost in the process of translation, a professional transcriptionist, bilingual and native Spanish-speaker translated the transcripts using forward-backward techniques to establish semantic equivalence in translation. We analysed transcripts using thematic analysis, an iterative process of coding the data in phases to find meaningful patterns ${ }^{(46,47)}$. Analytic phases included data familiarization, generation of initial codes, searching for and review of themes and patterns, and defining and naming themes. The qualitative data analysis software NVivo version 11 (QSR International Pty Ltd, 2015) was used to assist in coding, organizing and indexing of the qualitative data. All transcripts were read and reviewed by two authors who identified and generated initial codes, concepts and themes. Next, themes were reviewed, identified, defined and named ${ }^{(46,47)}$. Descriptive statistics and frequencies were calculated for the sociodemographic data and the Marin scale using Microsoft ${ }^{\circledR}$ Excel 2008.

\section{Results}

Seven FGD with twenty-eight Latino fathers of young children representing twenty-eight unique families were conducted. Participants' age ranged from 27 to 49 years (mean 34.2 (SD) $2 \cdot 8$ years). Participants had an average of two children (range: $1-4$ ) per household and 92.9\% ( $n$ 26) cohabited full-time with their children. Approximately $71.4 \%$ ( $n$ 20) had a high-school degree $(50.0 \% ; n$ 14) or general education diploma (GED; $21.4 \% ; n$ 6), and $60.7 \%$ ( $n$ 17) reported an annual family income of $\leq$ \$US 40000. Nearly all $(85.7 \% ; n$ 24) were foreign-born and had lived in the USA for an average of 14.3 (SD 2.7) years. The majority $(92.9 \% ; n$ 26) reported speaking primarily Spanish at home and their mean acculturation score was $2 \cdot 32$ (SD $0 \cdot 36$ ), indicating that they more closely identified with Latino culture, although they were close to 
'bicultural'. See Table 2 for additional information on the demographic characteristics of the fathers participating in the study.

Emergent themes related to fathers' beliefs, attitudes and practices related to eating, PA and SB of their young children are discussed below. Table 3 presents representative quotes illustrating each theme.

\section{Beliefs, attitudes and practices related to bealtby eating}

Fathers' definitions of bealthy eating

Fathers defined healthy eating in a variety of ways, although most offered a definition that focused on the importance of eating a balanced diet that included adequate amounts of fruits, vegetables and proteins. Fathers also spoke of limiting fried, 'junk' and fast foods, and several noted the importance of portion control.

\section{Fathers believe bealthy eating is important}

Across all FGD, fathers agreed about the importance of healthy eating for one's health and quality of life, including both adults and children. Moreover, several fathers viewed healthy eating as a lifestyle and reported that they

Table 2 Sociodemographic and acculturation characteristics of the study participants; Latino fathers ( $n$ 28) with at least one child aged 2-8 years, Rhode Island, USA, August-October 2016

\begin{tabular}{|c|c|c|c|c|}
\hline & Mean & SD & $n$ & $\%$ \\
\hline $\begin{array}{l}\text { Age (years) } \\
\text { US-born }\end{array}$ & $34 \cdot 2$ & $2 \cdot 8$ & - & - \\
\hline Yes & - & - & 4 & $14 \cdot 3$ \\
\hline No & - & - & 24 & 85.7 \\
\hline \multicolumn{5}{|l|}{ Country/territory of origin } \\
\hline Colombia & - & - & 9 & $32 \cdot 2$ \\
\hline Dominican Republic & - & - & 6 & 21.4 \\
\hline Puerto Rico & - & - & 4 & $14 \cdot 3$ \\
\hline Ecuador & - & - & 2 & $7 \cdot 1$ \\
\hline El Salvador & - & - & 2 & $7 \cdot 1$ \\
\hline Mexico & - & - & 2 & $7 \cdot 1$ \\
\hline Guatemala & - & - & 1 & $3 \cdot 6$ \\
\hline Venezuela & - & - & 1 & $3 \cdot 6$ \\
\hline Honduras & - & - & 1 & 3.6 \\
\hline Years in the USA* & $14 \cdot 3$ & $2 \cdot 7$ & - & - \\
\hline \multicolumn{5}{|l|}{ Predominant language spoken at home } \\
\hline Spanish & - & - & 26 & $92 \cdot 9$ \\
\hline English & - & - & 2 & $7 \cdot 1$ \\
\hline Marin scale acculturation score & $2 \cdot 32$ & 0.36 & - & - \\
\hline \multicolumn{5}{|l|}{ Marital status } \\
\hline Married & - & - & 26 & 92.9 \\
\hline Divorced & - & - & 2 & $7 \cdot 1$ \\
\hline \multicolumn{5}{|l|}{ Education level } \\
\hline Less than high school & - & - & 8 & 28.6 \\
\hline High-school degree & - & - & 14 & $50 \cdot 0$ \\
\hline General Education Development (GED) & - & - & 6 & $21 \cdot 4$ \\
\hline \multicolumn{5}{|l|}{ Annual household annual income (\$US) } \\
\hline$>40000$ and $\leq 50000$ & - & - & 11 & $39 \cdot 3$ \\
\hline$\leq 40000$ & - & - & 17 & $60 \cdot 7$ \\
\hline \multicolumn{5}{|l|}{ Currently employed } \\
\hline Yes & - & - & 26 & $92 \cdot 9$ \\
\hline No & - & - & 2 & $7 \cdot 1$ \\
\hline
\end{tabular}

*Only includes fathers not born in US states. consistently tried to eat a variety of healthy prepared foods. A few fathers noted the importance of children developing early healthy eating habits.

Fathers do not always eat bealthfully, but are aware of the need for improvement

Although there was consensus about the importance of healthy eating, some fathers spoke of the difficulties associated with this, especially given the availability and accessibility of unhealthy foods. Fathers also noted that a lack of time impacted their food choices and led them to select less healthy and more convenient options. In addition, a few fathers mentioned that it is 'easy to give in to unhealthy food choices when feeling stressed out'.

\section{Fathers' food parenting practices}

Continued effort. A few fathers spoke of their continued efforts to promote and support their children's healthy eating. Fathers explained that the food available outside their home is a constant 'temptation', impacts what types of foods their children want to eat and 'threatens' their children's healthy eating habits.

It is okay to indulge and eat unbealthfully once in a while. A few fathers reported that it is inevitable that their children will eat foods that are unhealthy, but that they tried to keep it to a minimum and mostly to the weekends. In addition, a couple of fathers suggested allowing 'unhealthy' food choices as 'once-in-a-while' reward.

Eating out. Some fathers noted that they rarely eat out, while others reported that they eat out frequently. Fathers most often went out to eat with their families on the weekends. When asked about the types of restaurants they frequent and foods ordered, fathers reported going to large chain restaurants, ethnic restaurants (e.g. Chinese, Hispanic) or out for pizza. Several fathers spoke of eating at fast-food restaurants, as it can be hard to eat out with young children.

\section{Fathers' involvement with and responsibilities for child feeding}

Fathers have a traditional view of motherbood. Most fathers who lived full-time with their children reported that their child's mother most often decided what their children and families ate, as well as how meals were prepared. A few fathers did note that it was a joint decision about the foods served to their families. The two fathers who did not co-reside with their children reported that they followed the lead of the mother regarding meals and child feeding. Some fathers explained that they preferred to let the mother make the decisions about child feeding as they felt mothers know how to best teach and instil healthy habits. A few fathers were more directly involved in decisions about child feeding due to the mothers' work schedule. 
Table 3 Focus group themes and supporting quotes from Latino fathers $(n 28)$ regarding their beliefs, attitudes and practices related eating, physical activity and sedentary behaviours of their children aged 2-8 years, Rhode Island, USA, August-October 2016

\begin{tabular}{l} 
Themes \\
\hline Healthy eating and food parenting practices \\
Definition, \\
Fathers' definitions of healthy eating
\end{tabular}

Fathers' definitions of healthy eating

\section{Importance}

Fathers believe healthy eating is important

\section{Personal practices}

Fathers do not always eat healthfully, but are aware of the need to improve their eating habits

Fathers' food parenting practices

Continued effort

It is okay to indulge and eat unhealthfully once in a while

Eating out

Fathers' involvement with and responsibilities for child feeding

Fathers have a traditional view of motherhood

Fathers' perceived barriers to children's healthy eating

Time constraints

Conflicting schedules

Convenience

Easy access and availability of unhealthy food choices
Representative quotes

'The diet should be healthy, should include vegetables and fruits, but necessarily everything. Healthy eating should include equilibrium.'

'I say it's no fast foods, not eating any fast-food meals ...'

'For me it's a balanced diet. It doesn't matter what you eat, it's about the portion.

'Healthy eating to me is a lifestyle, it's a way of life. It comes with so much more than just food. It's a big part of it, but healthy, it's just about knowing how to prepare the right meal and serving the right portion and at the right time.'

'Healthy eating is one of the most important things for one's health, and living healthy ... umm, it affects one's quality of life.'

'I think it's important that the kids learn to eat healthy, healthy foods when they are young .... it has an impact on their growth and health ...'

'I think it's important to try [eat healthfully], but sometimes you can't help it ... there's just so much food out there, everywhere you go, fast food, quick and cheap, and one makes bad choices ...'

'Many times I have to eat whatever is quickly available, fast and on-the-go ... so, the fastest and convenient is not healthiest ... pizza, tacos, hamburgers ...'

'It's a constant effort ... you need to keep trying to teach them [children] to eat healthy ... all of us [adults included].'

'I would like to change her [daughter] temptation. When we are driving she always wants to go to a fast-food place. I know that a lot of places now offer healthier choices in their menus ... salads, yoghurts, fruits ... [fast-food restaurants] now got things that are more natural, but still it's a temptation ...'

'You can't expect that children are going to eat healthy all the time. Every now and then they have some food that's not good [healthy] ... some fries, some candy and ice cream ... they are kids ...'

'I wish that my son would eat healthier, but he likes to eat some foods that are unhealthy, just like most kids ...'

'During the week we eat at home and during the weekends we go out ...'

'Chinese buffets, I love it. I love the shrimp. Sometimes we go to American restaurants, pizza, McDonald's once in a while, Burger King, those types of things. Sometimes we have had enough [home cooking] at home, so to vary we visit those places ...'

'If we got out, Wendy's or McDonald's. She [daughter] always goes out for pizza ...'

'When we go out to eat, it's usually a place where we can get some pizza, sometimes we take the kids to Applebee [chain restaurant] or stuff like that. Places that we know typically where they [children] like to eat ...'

'We try to go out to restaurants, but [with children] it's hard to have a sit-down meal. We get fast food, pizza ... always Wendy's for fast food ...'

'She [mother] is most direct contact when she is buying the food and when she chooses what we eat.'

'Yeah, usually is my wife. But we both help each other in that. But usually she makes the decision. Latino moms usually are the ones who do that ...'

'I like to follow the mother's lead ... it's just easier that way.'

'Sometimes during the week it's hard to find the time to prepare a meal. If my wife does not plan everything during the weekend, sometimes we just need to eat something on-the-go ....

'My wife likes to plan in advance, she does the shopping during the week and prepare some of the foods that take longer ... during the week our working hours can be long. My mother-in-law helps, but sometimes if we don't have things planned it's hard to cook a family meal.'

'My wife does a lot, it's crazy with the schedule at work, and sometimes it changes the last minute ... if I am not home it's hard ...'

'My wife has a more set schedule and she gets home at around $4 \mathrm{pm}$ and tries to get things started so that when I get home with the kids we can have a meal, but it can be hard.'

'Sometimes you need to get something quick after a long day of work .... the kids come home from school, my wife is still at work ... so, we just get some take-out ...'

'Every now and again, we just get something to eat before coming home - my wife, myself and the kids. Sometimes if I need to work late, my wife and the kids grab something ... some days she just can't do everything. I say, that's fine, no one is going to die because you are not cooking today ...'

'It's hard to resist sometimes ... nowadays it's so easy for kids [and adults] to eat fast food ... When I was growing up, bad food was fried food at home ...'

'You know, everywhere you go there is food, junk food, and it doesn't cost much ... sometimes you don't even think about it ... when you see the kids have eaten 2-3 junk foods already, a doughnut, a hamburger and fries, and soda ... just like that ... it's everywhere.' 
Table 3 Continued

Themes Representative quotes

Desire for changes

Fathers would like their children's eating habits to change

Fathers would like to change their eating habits

Physical activity and sedentary behaviours Definition

Fathers' definitions of active living

Importance

Fathers believe physical activity is important

Responsibility

Joint decisions about family activities

Parenting styles and practices

Permissive style and limit setting

Fathers are permissive of sedentary activities for their children and struggle to set limits

Involvement and engagement

Fathers report being involved and engaged in their children's physical activity 'l'd like to see some changes ... I would like my daughter to stop eating candy, and eat food. I also would like [daughter] to drink water and not soda.'

'You know, that little cookie here and candy there is not good, so probably that is one of the things I would like to change. Cut down on the sugar.'

'Have some lower intake in sugar, that is my wish ... but that is probably unrealistic ...'

'I guess my goal would be for them to eat more vegetables. More of a balanced diet, umm, you know, like we've touched upon throughout this talk ... a more balanced diet, and cutting down on the processed foods ...'

'I just want mine [child] to umm ... be in a balanced weight or at a healthy weight. With healthy, umm ... with healthy traditions and just I want them to eat right. I want them to grow up to be healthy adults. That they [children] are educated and have the knowledge of what is good for you, what's not good for you ... that's what I wish for them [children].'

'I am trying to change because before I could eat whatever I never worried about gaining weight. Since I'm not running as much and stuff like that, I'm noticing that I'm getting a little heavier.'

'I am not satisfied, because I think that relatively speaking, I am in the worst shape in my life. So, I think that from that point of reference ... how I used to be, I'm not there. So, currently, you know, I would like to change ... lose weight. I know I'm not going to go back to when I was eighteen, but definitely be in better shape, be you know, in shape.'

'I'm very interested in changing what I eat. I know I eat very unhealthy and that is something l've been trying to change actually. So, definitely want to change.'

'Active living to me would be somebody who goes outside, sees how beautiful life is, goes on a walk, exercise, doing activities with friends, family, just living life in a positive way, which doesn't involve just standing still. A body in motion will stay in motion. Just, moving around and trying to enjoy it.'

'Daily exercise, have a life that is not always siting near the television, do exercise for your whole body - walk, run and play sports. Now, I currently don't run, but walk in the morning.'

'Active living for me is staying active. Not necessarily doing exercise, but something like just walking. Even just going to the mall and just walking.'

'Being active is very important. You need to get your body moving to keep healthy and it really helps you mentally too ...'

'For the kids especially, I think they need to be moving, get themselves more alert, more engaged ... I think that the kids cannot spend a lot of time just sitting in front of the computer or playing video games ... they need to be active for their health.'

'Our body was made to be active! So, believe that being active is necessary to keep healthy!'

'I mean, we both decide in many ways. He is with her [mother] more than he is with me, but at the same time we have the same philosophy:

'We try to always do things together as a family. We go to the zoo, we go together, we go to the museum, we go together, so that is more shared decision ... when we are at home, then my wife is more in charge ...'

'You know with my daughter it's difficult ... she kind of like to play with dolls, do her colouring ... I am not going to interfere with that ... I just let her do what she wants and like. I just like to live in harmony ... why fight, right?'

'It's kind of hard because you want them to be active and play, but every kid is doing it and nowadays it's just part of their lives, so it's kind of hard to be always telling them no this, no that ...

'My son, he is very much video games, if he can play video games and stay indoors, that would be it, heaven for him! So, I constantly have to tell him, "get outside,

go out and play". Or, I have another rule with him. My son is twelve. You can play video games, but every time you win, or every time you get a next level, you have to do then push-ups. If you don't do, you don't play. It's a battle with everything ...'

'Well the kids nowadays, they love their video games and stuff like that So, we try to set some limits, but they still do it ... it's kind of inevitable to keep them off line ...'

'It is usually me when it comes to doing stuff with them ... usually mom comes home and she's kind like to keep everything in order kind of thing. Usually, the kids come and the house is ... house is in order and everything.'

'You know my wife wants to do more things with my daughter and I do with my son. I'll go hike with son and all those type of stuff.' 


\begin{tabular}{|c|c|}
\hline Themes & Representative quotes \\
\hline & $\begin{array}{l}\text { 'You know I kind of like to get my kids involved in some sports and play ... my son plays } \\
\text { karate, soccer, I really enjoy taking him to the activities, and that's also good because } \\
\text { it gives my wife a break to do her things around the house ...' }\end{array}$ \\
\hline \multicolumn{2}{|r|}{ 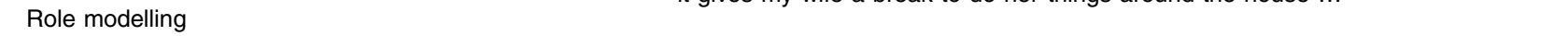 } \\
\hline $\begin{array}{l}\text { Fathers view themselves as physical activity role } \\
\text { models }\end{array}$ & $\begin{array}{l}\text { 'I know it's important for my kids to see we are active, you know, if they see you just } \\
\text { sitting around and watching TV, they will want to do that ... so, I try to take them out } \\
\text { whenever I can, just get outside and play ...' } \\
\text { 'My son loves soccer, and that's great because I grew up playing soccer, so he and I } \\
\text { play together, you know I like show him how to play ...' } \\
\text { 'We do some work yard together. I make my older and younger son cut the grass. My } \\
\text { two little ones help me out with the gardening stuff. Just working on the yard ...' }\end{array}$ \\
\hline \multicolumn{2}{|r|}{ 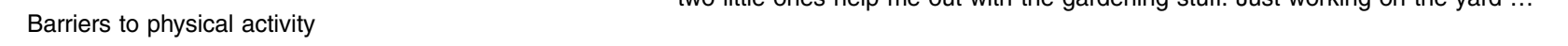 } \\
\hline \multirow[t]{4}{*}{$\begin{array}{l}\text { Fathers' perceptions of barriers to children being } \\
\text { physically active }\end{array}$} & $\begin{array}{l}\text { 'It's pretty much coordinating the schedule with her mom and myself. Sometimes it's } \\
\text { just hard to get everything going including get the kids out with all that needs to get } \\
\text { done.' }\end{array}$ \\
\hline & $\begin{array}{l}\text { 'You know living in New England the weather is always a factor. When the weather } \\
\text { changes you cannot go outside and be as active as you like, then you just wait, stay } \\
\text { more inside until the weather changes again.' }\end{array}$ \\
\hline & $\begin{array}{l}\text { 'Honestly, the factor is that it is a financial issue. I have four them [children] and I want } \\
\text { them to try everything and try every class in the world, but honestly, I can't afford it. } \\
\text { That is my issue ... I wish I could put them in every sport and give them every outlet to } \\
\text { find out what their talent is and what they are going to best at. But financially I can't do } \\
\text { it.' }\end{array}$ \\
\hline & $\begin{array}{l}\text { 'I think if you have access to different sports in terms of the city or the state because } \\
\text { sometimes you have to find the cheaper sport in your neighbourhood and it's not the } \\
\text { best for your child. I think every school, if you have more access, it would be better.' }\end{array}$ \\
\hline \multicolumn{2}{|r|}{ 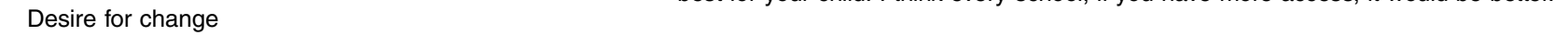 } \\
\hline \multirow[t]{3}{*}{$\begin{array}{l}\text { Fathers desire changes in their own physical activity } \\
\text { habits }\end{array}$} & $\begin{array}{l}\text { 'The physical activity that I am doing right now is none. I would like to return to soccer, } \\
\text { but I have a problem with my foot ... I don't know, I just like to go back to being active } \\
\text { again ...' }\end{array}$ \\
\hline & $\begin{array}{l}\text { 'I am not satisfied because I think that relatively speaking, I am in the worst shape in my } \\
\text { life. So, currently, you know, I would like to be in better shape. I used to be more } \\
\text { active than I am now.' }\end{array}$ \\
\hline & $\begin{array}{l}\text { 'I think I can still walk more. I would like to change that. I don't think I've been doing that } \\
\text { much lately and also maybe from home, if the weather doesn't allow me to walk, have } \\
\text { some treadmill, have something I can still be active even if I didn't get out of my house.' }\end{array}$ \\
\hline
\end{tabular}

TV, television.

Fathers' perceived barriers to children's healthy eating Fathers noted several barriers to their children's healthy eating, including parents having limited time for cooking home-made meals due to mothers' working long hours and conflicting family schedules. Additionally, some fathers spoke of children being 'picky eaters' and preferring foods such as chicken nuggets to more healthy options. Some fathers noted that easy access to and availability of inexpensive unhealthy foods that appealed to children's taste was a main influence in their children's eating habits.

Fathers would like their children's eating habits to change When asked about goals for their children, several fathers noted that they wanted their child to eat more healthfully and eat less 'junk' and 'sugary' foods, such as candy and soda. None the less, a couple of fathers did not think this was feasible because their children are exposed to and prefer these sorts of foods. Several fathers noted that although their children were good eaters, they would like their children to eat a greater variety of foods, including more fruits and vegetables, and less processed foods. A few fathers expressed concern for their children's current weight status and alluded to wanting their children to lose weight.
Fathers would like to change their eating habits

A few fathers explained that along with their children they also should eat more healthfully. Several fathers stated that they needed to pay attention to portion sizes and increase their fruit and vegetable intake. Furthermore, several fathers noted that they would like to lose weight and spoke of doing this by increasing their PA and watching what they eat.

\section{Beliefs, attitudes and practices related to physical activity and sedentary behaviours}

Fathers' definition of active living

When queried as to what active living means, about half of the participants provided a definition that focused on PA, while most others provided a broader definition that focused on being actively engaged in life, being mentally active, participating in family activities, being autonomous and/or working. A few fathers provided a hybrid definition that encompassed both being physically active and being engaged in life. A couple of fathers provided slightly different definitions of active living for children and parents, by defining active living for children as including interactions with friends as well as opportunities for intellectual growth. 


\section{Fathers believe physical activity is important}

Across all FGD, fathers explained that they believed that PA is important for health and for maintaining a healthy weight. Several fathers also mentioned the importance of PA for overall quality of life and mental health.

\section{Joint decisions about family activities}

Most fathers, but not all, reported that decisions regarding family activities were made by the family, with children, if old enough, being part of the decision-making process. Some fathers explained that they were more physically active than the mothers, who were more involved with household chores and keeping a family schedule. A few fathers noted that family activities sometimes unfold without planning and may be based on what the children feel like doing. A couple of fathers explained that they are usually active with their sons and their wives with their daughters.

\section{Fathers' parenting styles and physical activity parenting} practices

Fathers are permissive of sedentary activities for their children and struggle to set limits. Several fathers acknowledged engaging in sedentary behaviours with their children and being permissive of children's screentime behaviours. A few fathers noted that setting limits on screen time can be difficult, especially during the cold winter months, when children are more likely to spend more time inside. Some fathers described being permissive and allowing their children to have unlimited screen time. Furthermore, some fathers explained that playing video games, etc. is an acceptable part of children's lives nowadays and difficult to limit. A number of fathers noted that their children, especially their sons, enjoyed playing video games, using their electronic devices and watching TV, and that they often spent time with their children watching soccer matches on TV and playing video games. Fathers also spoke of other sedentary activities that their daughters enjoyed, such as playing with dolls and colouring.

Fathers report being involved and engaged in their children's physical activity. Overall, fathers felt that they were more involved and engaged in their children's PA than with feeding their children. Nevertheless, fathers reported that their children participated in both active and sedentary activities. They reported that their children liked playing soccer, swimming and playing outside. A few fathers noted that school had a positive impact on their children's PA levels by providing opportunities for active play.

Fathers view themselves as physical activity role models. Some fathers recognized the importance of modelling PA, but noted that they were not always as physically active as they should be. Nevertheless, a few fathers reported seeking out and being involved in adult sports programmes in their communities. Furthermore, a couple of fathers noted involving their children in household chores (e.g. yard work) that required their children to be active.

Fathers' perceptions of barriers to child being physically active

Not all fathers felt that there were barriers that prevented their children from being physically active. For example, several fathers reported that they lived in safe neighbourhoods that allowed their children to play freely in their yards and in the neighbourhood (e.g. access to parks). However, others noted barriers to PA including accessibility, cost of activities/programmes and cold weather. Additional noted barriers included having to schedule activities and having to work long hours.

\section{Fathers' desire to be more physically active}

A few fathers reported that they should be more physically active and spoke of being more active in the past. They noted that their reduced PA had contributed to their gaining weight. Only a limited number of fathers reported wanting their children to be more physically active.

\section{Discussion}

The current literature examining Latinos' parenting and their children's health-related behaviours focuses primarily on Latina mothers' beliefs, attitudes and practices related to their young children's eating, PA and $\mathrm{SB}^{(8,11,13,14-20,48-52)}$. To date, there is a paucity of information on these topics among Latino fathers. To address this gap, the present qualitative study explored Latino fathers' beliefs, attitudes and practices related to healthy eating, PA and SB of their young children among a predominantly immigrant sample.

Although we purposively invited fathers with young children (2-8 years) to participate in the study and developed the FGD guide to focus on food parenting practices and eating and PA habits of young children, it is worth noting that several fathers discussed these topics within the context of the whole family, including older and younger children. This is consistent with previous qualitative research and indicates the importance of the family within Latino communities ${ }^{(7,13,17,52)}$. It also suggests that the family should be considered the unit of change, as prevention of child overweight and obesity will not be successful without considering parents and children as a complete unit $^{(7,13,17,52)}$.

Recent trends suggest an increase in overall father involvement in childcare, with a few differences across racial and ethnic groups of fathers ${ }^{(21,23,25,26)}$. Research on cultural models of parenting practices suggests that Latinos' value of familism (e.g. family obligations, family reciprocity) is associated with behaviours that encourage fulfilling familial roles, such as taking care of children, which may lead to fathers being highly engaged in parenting $^{(26,53-56)}$. Studies conducted with Latino fathers in the 
USA suggest that they spend more time with their children in shared caregiving activities than White fathers ${ }^{(53-57)}$. A recent study with Latino parents and their 3-12-year-old children found that Latino fathers spent more time in caregiving activities than fathers from other ethnic groups ${ }^{(56)}$.

Latino fathers participating in the current study believed in the importance of healthy eating for their children, themselves and their families. Nevertheless, the majority reported a number of familial practices including eating out, getting take-out, etc. that have been linked to unhealthy eating habits and increased risk of overweight and obesity among children ${ }^{(37,38)}$. Moreover, several fathers reported a number of unhealthy personal eating habits (ignoring portion size, making unhealthy food choices, etc.) that may influence their children's eating behaviours, which most fathers wished would change. This finding is congruent with studies involving Latina mothers, and underscores the importance of childhood obesity prevention interventions to address parents' own eating behaviours $^{(11,13,14,16,17)}$. Given the importance of parental modelling in the development of children's eating behaviours, parenting interventions should incorporate opportunities to engage fathers and promote changes in fathers' own eating habits and food behaviours ${ }^{(17,32-35,56,58-60)}$.

Contrary to recent studies conducted with Caucasian, middle-income fathers, most Latino fathers participating in our study reported that they had limited responsibilities for organizing child meals and deciding what foods to feed the child ${ }^{(32-35)}$.

Our study found that Latino fathers appeared to allow their child's mother to make most decisions regarding their child's healthy eating and that they were more actively involved in their children's PA behaviours. This finding may reflect traditional parenting roles, with mothers bearing most responsibilities for child feeding. Nevertheless, a few fathers reported that they shared some child feeding responsibilities with the mother, especially when the mother worked long hours ${ }^{(37)}$.

Although more research is needed, our findings suggest that Latino fathers may be more interested in participating in interventions to promote $\mathrm{PA}$ and be less enticed to participate in interventions that focus solely on healthy eating. This should be taken into consideration when designing obesity prevention interventions involving Latino fathers. Future studies should continue to explore Latino fathers' roles and responsibilities for child feeding, and associations with children's eating habits and weight status. This information will be important for the design of obesity prevention interventions targeting Latino families that include fathers.

Consistent with previous research ${ }^{(62,63)}$, a few fathers in the current study expressed concerns for their children's weight status and alluded to the fact that they would like their children to lose weight. Appropriate assessment of a child's weight, followed by appropriate weight management strategies, is important for the prevention of obesity during childhood, as parents who misperceive their children's weight status are less likely to engage in interventions to reduce risk of paediatric obesity ${ }^{(62,63)}$. Previous studies with Latino mothers and fathers indicate that both parents are likely to misperceive their children's weight status, mostly underestimating their weight status $^{(37,62,63)}$. Future research should further explore Latino fathers' perceptions of their children's weight status and how their perceptions and attitudes towards their child's weight impact their food parenting practices and children's weight status. This information is important as evidence suggests parents who report more concerns about their child becoming overweight or obese also report more controlling food parenting practices (what and how much their child eats) that may have unintentional negative impacts (e.g. overly restricting food access) ${ }^{(10,32,34,48)}$.

Although our findings revealed that Latino fathers appeared to be more involved and engaged in children's PA than eating and feeding, we also found that fathers engaged in sedentary activities with their children, appeared permissive of children's SB and struggled to set limits on children's screen time. These findings are important given evidence of the influence of paternal parenting styles and practices on children's PA and screenviewing behaviours $^{(64-67)}$. Previous research suggests that parental attitudes towards and use of screen time, including parents' own screen-viewing habits, using screen viewing as a form of childcare (or babysitter), viewing screen time as a source of education and as a means of child relaxation, result in permissive styles towards their children's screen viewing ${ }^{(64-76)}$. Furthermore, our findings indicate that Latino fathers' ability to model healthy PA behaviours for their children may be limited by their lack of self-efficacy to participate in these behaviours themselves and indicate that interventions should focus not only on fathers' styles and practices, but also on helping fathers increase their self-efficacy for these behaviours. Existing research evidence combined with findings from the current study indicate the need for future research to further examine fathers' attitudes and personal behaviours, as well as the influence of Latino fathers' parenting styles and practices on their children's PA and SB. This information will be critical for designing interventions to decrease Latino children's screen time and SB.

Moreover, study findings also suggest possible gender differences in fathers' report of their daughters' and sons' $\mathrm{PA}$ and $\mathrm{SB}$, as well as their involvement and engagement in activities with their sons and daughters. Despite the small number of fathers who reported such differences, this is worth exploring further in future qualitative and quantitative research.

In summary, although the role of fathers in the promotion of their children's eating, PA and SB is a growing area of research, there is still limited information available on the role of minority fathers including Latinos ${ }^{(17,36-40)}$. The current study provides insights into the role of Latino 
fathers in promoting their children's eating, PA and SB within the family environment and contributes information that allows for a more complete picture of how Latino parents view eating and PA environments for their children. Given the central role of the family in the Latino culture, effective interventions targeting the promotion of healthy eating, PA and SB - and ultimately the prevention of child obesity and related chronic diseases - should take account of the role of fathers ${ }^{(13,17,36-39)}$.

Existing research suggests obesity prevention interventions designed for Latino children and families should target multiple behaviours (eating, PA, SB, sleep), be family-focused and involve both parents ${ }^{(77-83)}$. Research also suggests the importance of the intervention context (particularly, family constraints, ethnicity and parental motivation) in changing behaviours. Furthermore, interventions need to consider adapting programme content to accommodate cultural preferences ${ }^{(77-83)}$. In the case of Latinos, the use of culturally appropriate lay leaders (promotoras) to deliver interventions has shown to be efficacious. The present study adds to the existing literature and can inform the design of future research and the development of parenting and family-based interventions targeting Latino families ${ }^{(74,75)}$.

Study findings should be considered in light of some limitations. Findings are based on a non-random, purposeful and relatively small sample of low-income, Latino fathers recruited from community-based organizations located in a few cities in Rhode Island. Selection bias may have resulted in fathers having a heightened interest and awareness about eating, PA and SB. Furthermore, given that our recruitment strategy included recruiting participants from WIC clinics, it is possible that fathers might have been more inclined to believe that mothers were more knowledgeable of nutrition because of their participation in the WIC programme. Future research should utilize both qualitative and quantitative methods that address these study limitations by using different recruiting methods and exploring Latino fathers' beliefs, attitudes and practices related to eating, PA and SB from other communities across the USA. Nevertheless, the present qualitative study provided deep insight into primarily immigrant, Latino fathers' personal beliefs, attitudes and practices related to child eating, $\mathrm{PA}$ and SB and contributes new information to the current scant literature on Latino fathers and prevention of childhood obesity.

\section{Conclusions}

The present study provides new information on the beliefs and child feeding and PA practices of Latino fathers, most of whom were immigrants. The results may provide important targets for interventions aimed at promoting children's healthy eating and PA practices involving Latino fathers. Given the importance of the family in Latino culture and indication from the literature of the importance of the family context in the development of early healthy eating and PA habits, future research should further explore the role of fathers' parenting styles and practices in the development and support of children's early eating and PA habits. This information is needed to identify risk factors amenable to interventions and to design culturally appropriate parenting and family-based interventions targeting the home environment of Latino children and designed to meet the specific needs of this ethnic group.

\section{Acknowledgements}

Acknowledgements: We thank the fathers who participated in the study as well as the programmes and community-based agencies in Rhode Island, USA, for support in recruitment efforts. Financial support: This study was funded by the Joseph P. Healey Research Grant Program at the University of Massachusetts-Boston (Principal Investigator: A.C.L.). The funder had no role in the design, analysis or writing of this article. Conflict of interest: The authors declare that they have no conflict of interest. Authorship: All co-authors contributed to the work. A.C.L. designed the study, oversaw data collection, participated in data analysis, and led manuscript preparation and review. S.F.W. participated in interpretation of findings and manuscript preparation and review. M.A.M. participated in interpretation of findings and manuscript preparation and review. M.L.G. contributed to study design, led data analysis, and participated in interpretation of findings and manuscript preparation and review. All authors read and approved the final version of the manuscript. Ethics of human subject participation: The study was approved by the University of MassachusettsBoston Ethics Board (IRB\# 2013060) and all participants provided written, informed consent.

\section{References}

1. Ennis S, Rios-Vargas M \& Albert N (2011) The Hispanic population: 2010. https://www.census.gov/prod/cen2010/ briefs/c2010br-04.pdf (accessed June 2017).

2. Ogden CL, Carroll MD, Lawman HG et al. (2016) Trends in obesity prevalence among children and adolescents in the United States, 1988-1994 through 2013-2014. JAMA 315, 2292-2299.

3. Singh GK, Siahpush M, Hiatt RA et al. (2011) Dramatic increases in obesity and overweight prevalence and body mass index among ethnic-immigrant and social class groups in the United States, 1976-2008. J Community Health 36, 94-110.

4. Lindsay AC, Sussner KM, Kim J et al. (2006) The role of parents in preventing childhood obesity. Future Child 16, 169-186.

5. Lindsay AC, Greaney ML, Wallington SF et al. (2017) A review of early influences on physical activity and sedentary behaviors of preschool-age children in high-income countries. J Spec Pediatr Nurs 22, e12182. 
6. Lumeng JC, Taveras EM, Birch L et al. (2015) Prevention of obesity in infancy and early childhood: a National Institutes of Health workshop. JAMA Pediatr 169, 484-490.

7. Ochoa A \& Berge JM (2017) Home environmental influences on childhood obesity in the Latino population: a decade review of literature. J Immigr Minor Health 19, 430-447.

8. Schrempft S, van Jaarsveld CH, Fisher A et al. (2016) Maternal characteristics associated with the obesogenic quality of the home environment in early childhood. Appetite 107, 392-397.

9. Schrempft S, van Jaarsveld CH, Fisher A et al. (2015) The obesogenic quality of the home environment: associations with diet, physical activity, TV viewing, and BMI in preschool children. PLoS One 10, e0134490.

10. Sleddens EF, Kremers SP, Stafleu A et al. (2014) Food parenting practices and child dietary behavior. Prospective relations and the moderating role of general parenting. Appetite 79, 42-50.

11. Conlon BA, McGinn AP, Lounsbury DW et al. (2015) The role of parenting practices in the home environment among underserved youth. Child Obes 11, 394-405.

12. Birch LL \& Davison KK (2001) Family environmental factors influencing the developing behavioral controls of food intake and childhood overweight. Pediatr Clin North Am 48, 893-907.

13. Lindsay AC, Sussner KM, Greaney ML et al. (2011) Latina mothers' beliefs and practices related to weight status, feeding, and the development of child overweight. Public Health Nurs 28, 107-118.

14. Silva Garcia K, Power TG, Fisher JO et al. (2016) Latina mothers' influences on child appetite regulation. Appetite 103, 200-207.

15. Murashima M, Hoerr SL, Hughes SO et al. (2012) Feeding behaviors of low-income mothers: directive control relates to a lower BMI in children, and a nondirective control relates to a healthier diet in preschoolers. Am J Clin Nutr 95, 1031-1037.

16. James KS, Connelly CD, Rutkowski E et al. (2008) Familybased weight management with Latino mothers and children. J Spec Pediatr Nurs 13, 249-262.

17. Lora KR, Cheney M \& Branscum P (2017) Hispanic mothers' views of the fathers' role in promoting healthy behaviors at home: focus group findings. J Acad Nutr Diet 117, 914-922.

18. Thompson DA, Polk S, Cheah CS et al. (2015) Maternal beliefs and parenting practices regarding their preschool child's television viewing: an exploration in a sample of low-income Mexican-origin mothers. Clin Pediatr (Phila) 54, 862-870.

19. Matheson DM, Robinson TN, Varady A et al. (2006) Do Mexican-American mothers' food-related parenting practices influence their children's weight and dietary intake? J Am Diet Assoc 106, 1861-1865.

20. Sosa ET (2012) Mexican American mothers' perceptions of childhood obesity: a theory-guided systematic literature review. Health Educ Behav 39, 396-404.

21. Hofferth S \& Lee Y (2015) Family structure and trends in US fathers' time with children, 2003-2013. Fam Sci 6, 318-329.

22. Bianchi SM (2000) Maternal employment and time with children. Dramatic change or surprising continuity? Demography 37, 401-414.

23. Yeung WJ, Sandberg JF, Davis-Kean PE et al. (2001) Children's time with fathers in intact families. J Marriage Fam 63, 136-154.

24. Feinberg ME (2003) The internal structure and ecological context of coparenting. A framework for research and intervention. Parent Sci Pract 3, 95-131.

25. Raley S, Bianchi SM \& Wang W (2012) When do fathers care? Mothers' economic contribution and fathers' involvement in child care. AJS 117, 1422-1459.

26. Cabrera NJ, Hofferth SL \& Chae S (2011) Patterns and predictors of father-infant engagement across race/ethnic groups. Early Child Res Q 26, 365-375.
27. Davison KK, Gicevic S, Aftosmes-Tobio A et al. (2016) Fathers' representation in observational studies on parenting and childhood obesity: a systematic review and content analysis. Am J Public Health 106, e14-e21.

28. Khandpur N, Blaine RE, Fisher JO et al. (2014) Fathers' child feeding practices: a review of the evidence. Appetite $\mathbf{7 8}$, 110-121.

29. Freeman E, Fletcher R, Collins CE et al. (2012) Preventing and treating childhood obesity: time to target fathers. Int J Obes (Lond) 36, 12-15.

30. Fraser J, Skouteris H, McCabe M et al. (2011) Paternal influences on children's weight gain. A systematic review. Fathering 9, 252-267.

31. Harris TS \& Ramsey M (2015) Paternal modeling, household availability, and paternal intake as predictors of fruit, vegetable, and sweetened beverage consumption among African American children. Appetite 85, 171-177.

32. Vollmer RL, Adamsons K, Foster IS et al. (2015) Association of fathers' feeding practices and feeding style on preschool age children's diet quality, eating behavior and body mass index. Appetite 89, 274-281.

33. Khandpur N, Charles J, Blaine RE et al. (2016) Diversity in fathers' food parenting practices: a qualitative exploration within a heterogeneous sample. Appetite 101, 134-145.

34. Mallan KM, Daniels LA, Nothard M et al. (2014) Dads at the dinner table. A cross-sectional study of Australian fathers' child feeding perceptions and practices. Appetite 73, 40-44.

35. Morgan PJ, Collins CE, Plotnikoff RC et al. (2014) The 'Healthy Dads, Healthy Kids' community randomized controlled trial: a community-based healthy lifestyle program for fathers and their children. Prev Med 61, 90-99.

36. Guerrero AD, Chu L, Franke T et al. (2016) Father involvement in feeding interactions with their young children. Am J Health Behav 40, 221-230.

37. Parada H, Ayala GX, Horton LA et al. (2016) Latino fathers feeding-related parenting strategies on children's eating. Ecol Food Nutr 55, 292-307.

38. Penilla C, Tschann JM, Deardorff J et al. (2017) Fathers' feeding practices and children's weight status in Mexican American families. Appetite 117, 109-116.

39. Turner BJ, Navuluri N, Winkler P et al. (2014) A qualitative study of family healthy lifestyle behaviors of MexicanAmerican and Mexican immigrant fathers and mothers. J Acad Nutr Diet 114, 562-569.

40. Lora KR, Hubbs-Tait L, Ferris AM et al. (2016) AfricanAmerican and Hispanic children's beverage intake: differences in associations with desire to drink, fathers' feeding practices, and weight concerns. Appetite 107, 558-567.

41. Thompson DA, Vandewater EA, Matson PA et al. (2015) Young low-income ethnic minority children watch less television when their mothers regulate what they are viewing. Acta Paediatr 104, 300-305.

42. Lindsay AC, Greaney ML, Wallington SF et al. (2017) Depressive symptoms and length of US residency are associated with obesity among low-income Latina mothers: a cross-sectional analysis. Int J Environ Res Public Health 14, E869.

43. Kidd PS \& Parshall MB (2000) Getting the focus and the group: enhancing analytical rigor in focus group research. Qual Health Res 10, 293-308.

44. Miles M \& Huberman A (1994) Qualitative Data Analysis, 2nd ed. Thousand Oaks, CA: SAGE Publications, Inc.

45. Marin G, Sabogal F \& Marin BV (1987) Development of a short acculturation scale for Hispanics. Hisp J Behav Sci 9 , 183-205.

46. Ritchie J \& Spencer L (1994) Qualitative data analysis for applied policy research. In Analysing Qualitative Data, pp. 173-194 [A Bryman and R Burgess, editors]. London: Routledge.

47. Vaismoradi M, Turunen H \& Bondas T (2013) Content analysis and thematic analysis: implications for conducting a qualitative descriptive study. Nurs Health Sci 15, 398-405. 
48. Tschann JM, Martinez SM, Penilla C et al. (2015) Parental feeding practices and child weight status in MexicanAmerican families: a longitudinal analysis. Int J Behav Nutr Phys Act 12, 66.

49. Mejia de Grubb MC, Salemi JL, Gonzalez SJ et al. (2016) Parenting style and perceptions of children's weight among US Hispanics: a qualitative analysis. Health Promot Int daw050, https://doi.org/10.1093/heapro/daw050

50. Santiago-Torres M, Adams AK, Carrel AL et al. (2014) Home food availability, parental dietary intake, and familial eating habits influence the diet quality of urban Hispanic children. Child Obes 10, 408-415.

51. Olvera N \& Power TG (2010) Brief report: parenting styles and obesity in Mexican American children: a longitudinal study. J Pediatr Psychol 35, 243-249.

52. Lindsay AC, Sussner KM, Greaney ML et al. (2009) Influence of social context on eating, physical activity, and sedentary behaviors of Latina mothers and their preschool-age children. Health Educ Behav 36, 81-96.

53. Mirande JL (1997) Hombres y Machos: Masculinity and Latino Culture. Boulder, CO: Westview.

54. Roopnarine JL \& Ahmeduzzaman M (1993) Puerto Rican fathers' involvement with their preschool-age children. Hisp J Behav Sci 15, 96-107.

55. Toth JF \& Xu X (1999) Ethnic and cultural diversity in fathers' involvement: a racial/ethnic comparison of African American, Hispanic, and White fathers. Youth Soc 31, 76-99.

56. Hofferth SL (2003) Race/ethnic differences in father engagement in two-parent families: culture, context, or economy. J Fam Issues 24, 185-216.

57. Mirande A (1991) Ethnicity and fatherhood. In Fatherhood and Families in Cultural Context: Focus on Men, pp. 53-82 [FQ Bozett and S Hanson, editors]. New York: Springer.

58. Harris TS \& Ramsey M (2015) Paternal modeling, household availability, and paternal intake as predictors of fruit, vegetable, and sweetened beverage consumption among African American children. Appetite 85, 171-177.

59. Webber KJ \& Loescher LJ (2013) A systematic review of parent role modeling of healthy eating and physical activity for their young African American children. I Spec Pediatr Nurs 18, 173-188.

60. Tibbs T, Haire-Joshu D, Schechtman KB et al. (2001) The relationship between parental modeling, eating patterns, and dietary intake among African-American parents. $J \mathrm{Am}$ Diet Assoc 101, 535-541.

61. Arredondo EM, Elder JP, Ayala GX et al. (2006) Is parenting style related to children's healthy eating and physical activity in Latino families? Health Educ Res 21, 862-871.

62. Myers S \& Vargas Z (2000) Parental perceptions of the preschool obese child. Pediatr Nurs 26, 23-30.

63. Gauthier KI \& Gance-Cleveland B (2015) Hispanic parental perceptions of child weight in preschool-aged children: an integrated review. Child Obes 11, 549-559.

64. Jago R, Thompson JL, Sebire SJ et al. (2014) Cross-sectional associations between the screen-time of parents and young children: differences by parent and child gender and day of the week. Int J Behav Nutr Phys Act 11, 54.

65. Jago R, Zahra J, Edwards MJ et al. (2016) Managing the screen-viewing behaviours of children aged 5-6 years: a qualitative analysis of parental strategies. BMJ Open 6, e010355.

66. Jago R, Sebire SJ, Lucas PJ et al. (2013) Parental modelling, media equipment and screen-viewing among young children: cross-sectional study. BMJ Open 3, e002593.

67. Lloyd AB, Lubans DR, Plotnikoff RC et al. (2014) Maternal and paternal parenting practices and their influence on children's adiposity, screen-time, diet and physical activity. Appetite 79, 149-157.

68. McClendon ME, Umstattd Meyer MR, Ylitalo KR et al. (2017) Physical activity of Mexican-heritage youth during the summer and school-year: the role of parenting strategies. $J$ Community Health (Epublication ahead of print version).

69. Rodríguez-Oliveros G, Haines J, Ortega-Altamirano D et al. (2011) Obesity determinants in Mexican preschool children: parental perceptions and practices related to feeding and physical activity. Arch Med Res 42, 532-539.

70. Asplund KM, Kair LR, Arain YH et al. (2015) Early childhood screen time and parental attitudes toward child television viewing in a low-income Latino population attending the Special Supplemental Nutrition Program for Women, Infants, and Children. Child Obes 11, 590-599.

71. O'Connor TM, Cerin E, Lee RE et al. (2014) Environmental and cultural correlates of physical activity parenting practices among Latino parents with preschool-aged children: NiñosActivos. BMC Public Health 14, 707.

72. O'Connor TM, Chen TA, Baranowski J et al. (2013) Physical activity and screen-media-related parenting practices have different associations with children's objectively measured physical activity. Child Obes 9, 446-453.

73. Jago R, Sebire SJ, Edwards MJ et al. (2013) Parental TV viewing, parental self-efficacy, media equipment and TV viewing among preschool children. Eur J Pediatr 172, $1543-1545$.

74. Jago R, Wood L, Zahra J et al. (2015) Parental control, nurturance, self-efficacy, and screen viewing among 5- to 6year-old children: a cross-sectional mediation analysis to inform potential behavior change strategies. Child Obes 11, $139-147$.

75. Johnson L, Chen TA, Hughes SO et al. (2015) The association of parent's outcome expectations for child TV viewing with parenting practices and child TV viewing: an examination using path analysis. Int J Behav Nutr Phys Act 12, 70.

76. Pearson N, Salmon J, Crawford D et al. (2011) Are parental concerns for child TV viewing associated with child TV viewing and the home sedentary environment? Int J Behav Nutr Phys Act 8, 102.

77. Crespo NC, Elder JP, Ayala GX et al. (2012) Results of a multi-level intervention to prevent and control childhood obesity among Latino children: the Aventuras Para Niños Study. Ann Behav Med 43, 84-100.

78. Ayala GX, Elder JP, Campbell NR et al. (2010) Longitudinal intervention effects on parenting of the Aventuras para Niños study. Am J Prev Med 38, 154-162.

79. Falbe J, Cadiz AA, Tantoco NK et al. (2015) Active and Healthy Families: a randomized controlled trial of a culturally tailored obesity intervention for Latino children. Acad Pediatr 15, 386-395.

80. Kaiser L, Martinez J, Horowitz M et al. (2015) Adaptation of a culturally relevant nutrition and physical activity program for low-income, Mexican-origin parents with young children. Prev Chronic Dis 12, E72.

81. de la Torre A, Sadeghi B, Green RD, Kaiser LL et al. (2013) Niños Sanos, Familia Sana: Mexican immigrant study protocol for a multifaceted CBPR intervention to combat childhood obesity in two rural California towns. BMC Public Health 13, 1033.

82. Zoorob R, Buchowski MS, Beech BM et al. (2013) Healthy Families Study: design of a childhood obesity prevention trial for Hispanic families. Contemp Clin Trials 35, 108-121.

83. Schmied E, Parada H, Horton L et al. (2015) A process evaluation of an efficacious family-based intervention to promote healthy eating: the Entre Familia: Reflejos de Salud Study. Health Educ Behav 42, 583-592. 